\title{
Pulp capping with mineral trioxide aggregate or Biodentine: a comparison of mineralized barrier formation and inflammatory and degenerative events
}

\section{Magda de Sousa REIS(a) iD \\ Roberta Kochenborger \\ SCARPARO(b) \\ Bruna SIGNOR(b) ID \\ Juliana Troglio BOLZAN(c) iD \\ Liviu STEIER ${ }^{(d)}$ iD \\ José Antonio Poli de \\ FIGUEIREDO(b)}

(a) Universidade de Santa Cruz do Sul - Unisc, Department of Health Sciences, Santa Cruz do Sul, RS, Brazil.

(b) Universidade Federal do Rio Grande do Sul - UFRGS, School of Dentistry, Department of Conservative Dentistry, Porto Alegre, RS, Brazil.

(c) Pontifícia Universidade Católica do Riio Grande do Sul - PUCRS, Clinical Department, Porto Alegre, RS, Brazil.

(d) University of Pennsylvania, School of Dental Medicine, Division of Restorative Dentistry, Philadelphia, PA, USA.

Declaration of Interests: The authors certify that they have no commercial or associative interest that represents a conflict of interest in connection with the manuscript.

\section{Corresponding Author:}

Roberta Kochenborger Scarparo

E-mail: roberta.scarparo@ufrgs.br

https://doi.org/10.1590/1807-3107bor-2021.vol35.0118

Submitted: May 21, 2020

Accepted for publication: March 1, 2021

Last revision: April 23, 2021

\begin{abstract}
Biodentine in endodontic practice has been widely investigated, but comprehensive histological descriptions of degenerative and inflammatory responses are not covered in most of the studies that compare pulp capping materials. This study aimed to evaluate pulpal responses to mineral trioxide aggregate (MTA Angelus) and Biodentine, focusing on mineralized barrier formation and on inflammatory and degenerative events. 80 male Wistar rats were assigned to 5 groups, according to the materials used for pulp capping and coronal sealing $(n=8$ per group/period). The lower first molars were mechanically exposed, capped with either MTA or Biodentine, and restored with silver amalgam. In an additional test group, the teeth were capped and sealed with Biodentine. The teeth capped with gutta-percha and restored with silver amalgam served as positive control, whereas untreated teeth served as negative control. Pulpal responses and coronal sealing were evaluated after 14 or 21 days. Data was statistically analyzed by the Kruskal-Wallis and Dunn's post hoc tests $(p<0.05)$. Biodentine and MTA presented satisfactory results, showing a milder inflammatory response $(p<0.0001)$ and more pronounced formation of mineralized barrier $(p<0.0001)$ compared to the teeth capped with gutta-percha. As a restorative material, Biodentine kept coronal sealing in only $37.5 \%$ of the samples. Biodentine showed favorable properties in vital pulp therapy, being similar to MTA. However, it was not effective in protecting dental pulp from microleakage during the experimental period.
\end{abstract}

Keywords: Endodontics; Dental Pulp Capping; Dental Materials.

\section{Introduction}

Through the application of biocompatible materials, vital pulp therapy promotes the differentiation of mineralized tissue-producing cells $s^{1,2}$ and the formation of a calcified barrier, thus protecting the pulp from microleakage and favoring healing.,4 To achieve these goals, a number of properties, including low toxicity, dimensional stability, sealing ability, ease of handling, radiopacity, and absence of carcinogenic and genotoxic potential are required. ${ }^{5-8}$

For decades, the capping material that best meets these criteria has been calcium hydroxide, which exerts biological activity through the dissociation 
- Pulp capping with mineral trioxide aggregate or Biodentine: a comparison of mineralized barrier formation and inflammatory and degenerative events

of calcium and hydroxyl ions. ${ }^{6,8,9}$ However, when used as a powder or mixed with aqueous vehicles, it has poor stability, which affects sealing ability. On the other hand, cement formulations of calcium hydroxide are not pure, and the release of ions is compromised. ${ }^{6,8}$ The use of mineral trioxide aggregate (MTA) in vital pulp therapy has been suggested because of its sealing ability, biocompatibility, antibacterial activity, and capacity to stimulate dentin neoformation, ${ }^{2,47,7,10}$ and has been considered more effective than calcium hydroxide. ${ }^{11}$ Nevertheless, difficulties with handling, long setting time, high cost, and tooth discoloration ${ }^{5,12}$ have encouraged the development of alternative materials.

Biodentine (Septodont, Saint Maur-des-Fossées, France) is a tricalcium silicate-based material with a similar composition to that of MTA, but it offers some advantages in terms of handling and chemomechanical properties. Greater absorption and concentration of calcium ions in the dentin, lower setting time, greater microhardness, and resistance to compressive loading are some of these advantages. ${ }^{13,14}$ Studies evaluating cytotoxicity, antimicrobial activity, genotoxicity, and physical characteristics have indicated favorable properties ${ }^{13,15,16,17}$ in addition to the ability of Biodentine to induce odontoblast-like cell differentiation, thus stimulating the formation of dentin-like tissue. ${ }^{10,14,18,19}$ Therefore, amongst other clinical indications, it has been suggested that Biodentine can be used for pulp capping ${ }^{14,20,21,22}$ and in temporary dental restorations. ${ }^{23,24,25}$

The use of Biodentine in endodontic practice has been widely investigated in vitro, ${ }^{26}$ in animal experiments ${ }^{27,28,29}$ and in clinical studies. ${ }^{30,31}$ However, comprehensive histological descriptions of degenerative and inflammatory responses are not covered in most of the studies that compare pulp capping materials, once the intensity of inflammation is often used as the only measure of dental pulp damage after capping procedures..$^{20,32}$

Biological test models may provide compelling evidence that Biodentine offers advantages over other available alternatives for vital pulp therapy. The present investigation aims to evaluate pulpal tissue responses in Wistar rats after capping with either Biodentine or MTA (MTA Angelus, Londrina, PR,
Brazil), focusing on mineralized barrier formation and inflammatory and degenerative events. Moreover, the ability of Biodentine to maintain coronal sealing and to protect the pulp from microleakage in the absence of a definitive restoration is also evaluated.

\section{Methodology}

This study was approved by the Animal Care and Use Committee (Process: 12/00320) of the Pontifical Catholic University of Rio Grande do Sul, Brazil. Eighty male Wistar rats weighing approximately $250 \mathrm{~g}$ were employed ( $\mathrm{n}=8$ per group/period).

Prior to the experimental procedures, the animals were anesthetized intraperitoneally with ketamine (Dopalen, Ceva, Paulínea, Brazil) and xylazine (Rompum, Bayer, São Paulo, Brazil) with 80 and $20 \mathrm{mg}$ / $\mathrm{kg}$ of body weight, respectively. Mouth opening was achieved by using a previously designed device, ${ }^{33}$ and the tissues were pulled away with the aid of dental pliers.

The dental pulp of the right lower first molars was mechanically exposed at the center of the occlusal surface using a new round diamond bur (ISO \# 1011 HL, KG Sorensen, Cotia, Brazil) for each tooth, at high speed and under water cooling. The resulting cavities had nearly the same size (about $1 \mathrm{~mm}$ ) as the bur tip. Visual examination under magnification with clinical loupes and clinical inspection with Rhein probes (Odous de Deus, Belo Horizonte, Brazil) confirmed pulp exposure. Bleeding was controlled through copious irrigation with distilled water and by using wet cotton pellets with gentle pressure.

After that, teeth were divided into five groups, according to the capping and sealing materials, as follows (Figure 1):

- MTA/SA group: teeth were sealed with MTA (Angelus, Londrina, PR, Brazil) and restored with silver amalgam (DFL, Rio de Janeiro, RJ, Brazil);

- Biodentine/SA: teeth were sealed calcium silicate cement Biodentine ${ }^{\mathrm{TM}}$ (Septodont, Saint Maur-des-Fosses, France) and restored with silver amalgam;

- Biodentine: teeth were both sealed and restored with Biodentine; 
- Gutta/SA: teeth were sealed with Gutta-percha (Dentsply, Petrópolis, RJ, Brazil) and restored with silver amalgam (positive control group);

- Untreated healthy teeth (negative control group). All materials were manipulated as instructed by the manufacturers.

After experimental periods of 14 and 21 days, the animals were euthanized by inhalation of isoflurane, and the jaws were dissected for photographic, radiographic, and histological evaluation.

\section{Photographic and radiographic analysis of coronal sealing}

The marginal sealing produced by silver amalgam and Biodentine was macroscopically evaluated using photographs and radiographs. After jaw dissection, the specimens were positioned and fastened onto a table with utility wax strips. Afterwards, they were photographed using a camera (Canon EOS 500 D, Rebel T1i Tokyo, Japan) adjusted to manual mode (1/200 and F/32 with 2-second temporization) attached to a tripod at a $30-\mathrm{cm}$ distance from the sample. The camera was positioned in such a way that it enabled the acquisition of images of the entire occlusal surface.

Radiographs were taken using an X-ray unit (Gnatus, Ribeirão Preto, Brazil) operated at $70 \mathrm{kVp}$.
A phosphor plate size 2 (Gendex, Chicago, USA) and an exposure time of $0.2 \mathrm{~s}$ were employed. Samples were positioned so as to achieve a perpendicular angle between the buccal surface and X-ray exposure. A focal distance of $30 \mathrm{~cm}$ was established. A digital X-ray system (Denoptix/Gendex, Chicago, USA) was used to capture the images, which were scanned at a 300-dpi resolution and saved in TIFF format.

Radiographic and photographic images were analyzed by a blinded and calibrated examiner (ICC $=0.90$ ), who classified the coronal sealing of each sample according to the criteria described in Table 1.

\section{Histological processing and analysis}

After photographic and radiographic acquisitions, the samples were fixed in $10 \%$ buffered formaldehyde for $24 \mathrm{~h}$. The specimens were then decalcified with 17\% EDTA for 5 weeks. Finally, they were dehydrated in ascending concentrations of ethanol and embedded in paraffin. $5-\mu \mathrm{m}$-thick semi-serial sections were obtained in a buccolingual direction and stained with hematoxylin and eosin (HE). For each sample, the three sections that best allowed the observation of the pulp exposure area were selected for histological analysis. A capture system (Motic Plus Moticam- 5 megapixels) was used for image

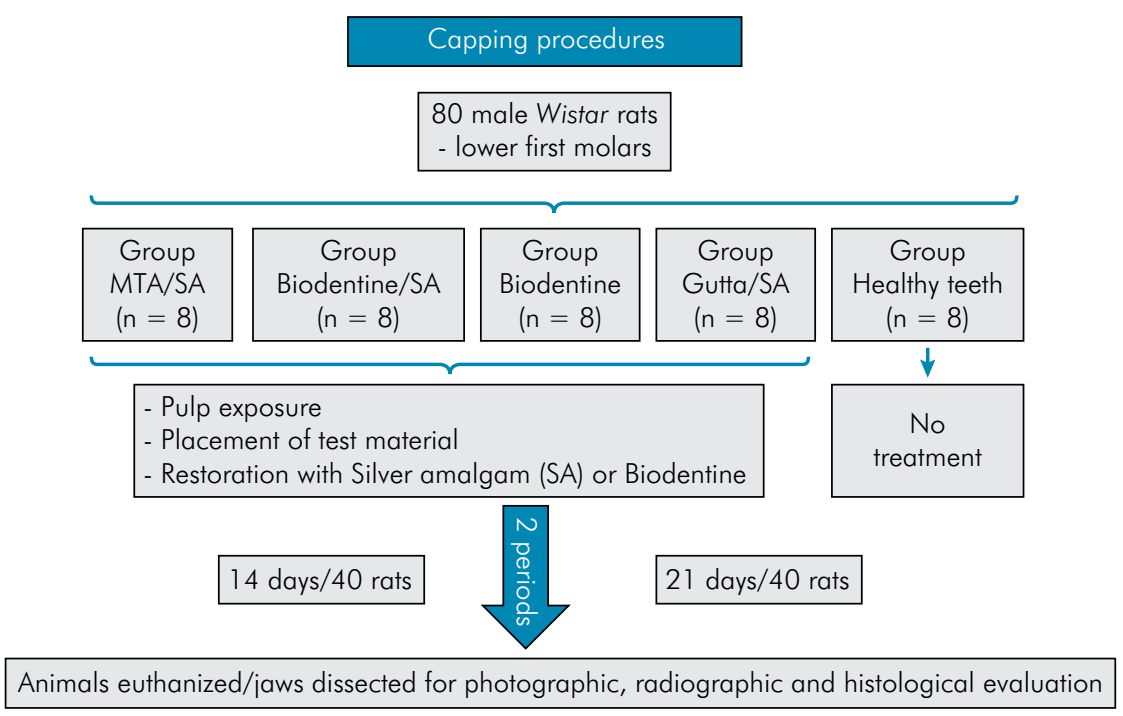

Figure 1. Flowchart showing the study design. A total of 80 animals were divided according to the experimental procedures and periods ( $n=8$ per group/period). 
- Pulp capping with mineral trioxide aggregate or Biodentine: a comparison of mineralized barrier formation and inflammatory and degenerative events

storage. The histological samples were subjected to descriptive analysis. Additionally, the samples were classified into scores by a blinded and calibrated examiner (kappa $>0.90$ for all variables) according to the extent and intensity of inflammation and to pulpal degenerative events (Table 2). Despite the fact of being semi-serial section, which does not allow the visualization of a complete dentin area formation (dentin bridge), these terms were used for didactic purposes.

Table 1. Qualitative criteria for restoration following pulpotomy.

\begin{tabular}{lc}
\hline Restoration quality & Description \\
\hline Intact & $\begin{array}{c}\text { Intact restorative material within cavity or } \\
\text { slight recession }\end{array}$ \\
Recessed & $\begin{array}{c}\text { Evident recession of dental material and } \\
\text { restoration compromised by fracture }\end{array}$ \\
Absent & Restorative material not visible within cavity \\
\hline
\end{tabular}

\section{Statistical analysis}

Comparisons of histological features among the groups were performed using the Kruskal-Wallis and Dunn's post hoc tests, using Graphpad Prism 6.0 Statistical Software (GraphPad Software Inc., San Diego, USA). Differences were considered significant when $\mathrm{p}<0.05$.

\section{Results}

\section{Coronal sealing}

The teeth restored with amalgam remained intact in $91.66 \%$ of the samples. By contrast, only $18.75 \%$ of those teeth sealed with Biodentine presented intact restoration or mild abrasion, $43.75 \%$ showed material degradation/fracture, and $37.5 \%$ had complete loss of restoration after the experimental periods (Table 3 and Figure 2G).

Table 2. Scoring system for pulpal procedures and tissue response.

\begin{tabular}{|c|c|}
\hline Scores & Inflammation pulp intensity \\
\hline 1 & Absence of inflammation. \\
\hline 2 & Mild inflammatory infiltration, predominantly mononuclear, restricted by fibercondensation; underlying tissue with sparse inflammatory cells. \\
\hline 3 & $\begin{array}{c}\text { Moderate inflammatory infiltrate, with infiltrates of mononuclear cells, or with sparse neutrophils and/or eosinophils, restricted by } \\
\text { condensation fibers. }\end{array}$ \\
\hline 4 & $\begin{array}{c}\text { Moderate inflammatory infiltrate, with infiltrates of mononuclear cells, or with sparse neutrophils and/or eosinophils, not restricted by } \\
\text { condensation fibers. }\end{array}$ \\
\hline 5 & $\begin{array}{l}\text { Severe inflammatory infiltrate, with tissue necrosis or abscess, with predominance of neutrophils and/or eosinophils, or a mononuclear } \\
\text { infiltrate extending towards the whole pulp tissue. }\end{array}$ \\
\hline Scores & Inflammation pulp (extension) \\
\hline 1 & Absence of inflammation. \\
\hline 2 & Inflammation restricted to area of exposed pulp. \\
\hline 3 & Inflammation restricted the access of the root canals. \\
\hline 4 & Inflammation affecting the cervical third of the root canals. \\
\hline 5 & Inflammation affecting the middle and apical third. \\
\hline Scores & Degenerative events \\
\hline 1 & Slight fiber condensation; underlying tissue with slightly condensed extracellular matrix. \\
\hline 2 & Moderate fiber condensation; underlying tissue with presence of slightly condensed extracellular matrix, displaying small areas of hyalinization. \\
\hline 3 & $\begin{array}{c}\text { Moderate fiber condensation; underlying tissue altered by condensed extracellular matrix (with small areas of hyalinization) and small } \\
\text { clusters of calcium degeneration (not related to odontoblastic layer). }\end{array}$ \\
\hline 4 & Extensive hyalinization areas and/or calcific degeneration towards pulp chamber and radicular pulp. \\
\hline 5 & Total or partial pulp degradation \\
\hline Scores & Dentin bridge \\
\hline 1 & Complete dentin bridge formation (regular and thick) at the exposure area. \\
\hline 2 & Incomplete dentin bridge formation (irregular or thin) at the exposure area. \\
\hline 3 & Complete or incomplete dentin bridge together with osteodentin at the exposure area \\
\hline 4 & Complete or incomplete dentin bridge together with osteodentin at the exposure area and invading root canal. \\
\hline 5 & Absence of dentin bridge \\
\hline
\end{tabular}


Table 3. Evaluation of restorative material (Silver amalgam and Biodentine) following pulpotomy.

\begin{tabular}{ccccc}
\hline Periods & Groups $(\mathrm{n}=8)$ & Intact & Recessed & Absent \\
\hline \multirow{4}{*}{14 days } & Gutta/SA & 6 & 2 & - \\
& MTA/SA & 8 & - & - \\
& Biodentine/SA & 8 & - & - \\
& Biodentine & 2 & 3 & 3 \\
\hline \multirow{4}{*}{21 days } & Gutta/SA & 6 & 2 & - \\
& MTA/SA & 8 & - & - \\
& Biodentine/SA & 8 & - & - \\
& Biodentine & 1 & 4 & 3 \\
\hline
\end{tabular}

\section{Histological analysis}

The histological analysis of pulp tissue reaction to the tested biomaterials (MTA/SA, Biodoentine/SA and Biodentine groups) revealed significant differences in inflammatory events (intensity and extent) $(p<0.0001)$, degenerative events $(p<0.05$ and $p<0.01$ at 14 and 21 days, respectively), and formation of dentin-like bridge $(\mathrm{p}<0.0001)$ when compared with the positive control (Gutta/SA group) - Figures 2A, $3 \mathrm{~A}$ and $4 \mathrm{~A}$.

Negative control group (healthy teeth) samples served as a parameter of pulp tissue homeostasis and revealed absence of inflammation and of degenerative events (Figure 3B).When gutta-percha was placed in contact with the dental pulp, severe inflammatory reaction, abscess formation, and necrosis were observed, whereas most of the samples capped with either MTA or Biodentine showed slight inflammatory infiltration, predominantly comprised of mononuclear cells, especially when silver amalgam was used as the coronal sealing material. In the 21- day experimental period, samples capped with Biodentine alone (Biodentine group) showed more intense inflammatory infiltrate compared to the ones capped with Biodentine and sealed with silver amalgam (Biodentine/SA group) (Figure 2B-F).

Some samples in contact with MTA or Biodentine showed moderate inflammation with neutrophils and/or sparse eosinophils, but the inflammatory reaction was frequently limited by fibrous condensation and remained restricted to the area of pulp exposure or next to the entrance of the root canals. On the other hand, in the positive control group (Gutta/SA), inflammatory reaction reached the middle and apical third of the root canals in approximately half of the samples (Figure $2 \mathrm{~B}-\mathrm{F}$ ).

Regarding the occurrence of degenerative processes in response to the materials (MTA and Biodentine), moderate fibrous condensation, hyalinized areas, and calcifications were observed at the pulp cervical third. Severe pulp degeneration was noted along the root canal length in the positive control group (Gutta/SA) (Figure 3B-F).

Dentin-like bridge formation at the exposure site was observed at 14 and 21 days in all groups treated with biomaterials (MTA/SA, Biodentine/SA, and Biodentine), but it was not detected in any of the positive control samples (Figure 4B-D).

\section{Discussion}

The present investigation verified that Biodentine and MTA were similar, promoting the formation of a hard tissue barrier, producing acceptable levels of inflammatory response, and maintaining pulp vitality when used as capping agents. These outcomes are in accordance with those of other studies on MTA $4,5,7,34$ that allowed comparing pulpal responses of well-established and recently introduced materials. Moreover, the current study showed that Biodentine had some difficulties in protecting the dental pulp from microleakage when used as a restorative material.

The suitability of rat molars to evaluate the results of vital pulp therapy has been confirmed in several studies, ${ }^{9,32}$ considering similarities to human teeth in terms of anatomical, physiological, biological, and histological characteristics. Moreover, this animal model allows the analysis of pulp, furcation and periapical tissue responses in shorter periods because rats have a faster metabolism than do other animals. ${ }^{933,35,36,37}$ As previously demonstrated ${ }^{21,33}$ and confirmed herein, post-experimental periods of 14 days are adequate to the evaluation of dental pulp inflammatory and degenerative responses to biomaterials, while 21-day experimental periods are usually suitable for observing the formation of hard tissue barriers, although some samples exhibited hard tissue at 14 days. Reports of longer periods to obtain the same outcomes are available in miniature pigs, dogs, and humans. ${ }^{20,38,39}$ 
- Pulp capping with mineral trioxide aggregate or Biodentine: a comparison of mineralized barrier formation and inflammatory and degenerative events

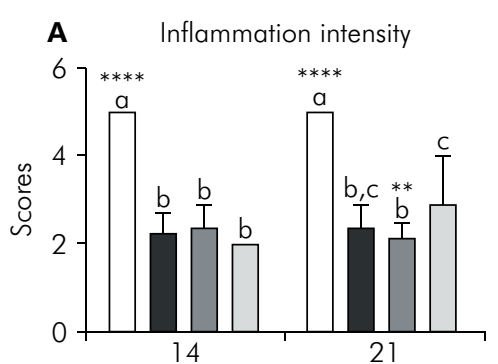

Days post treatment

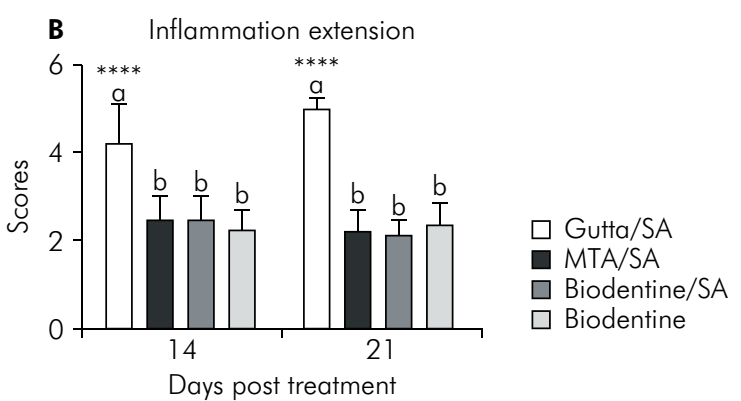

Days post treatment
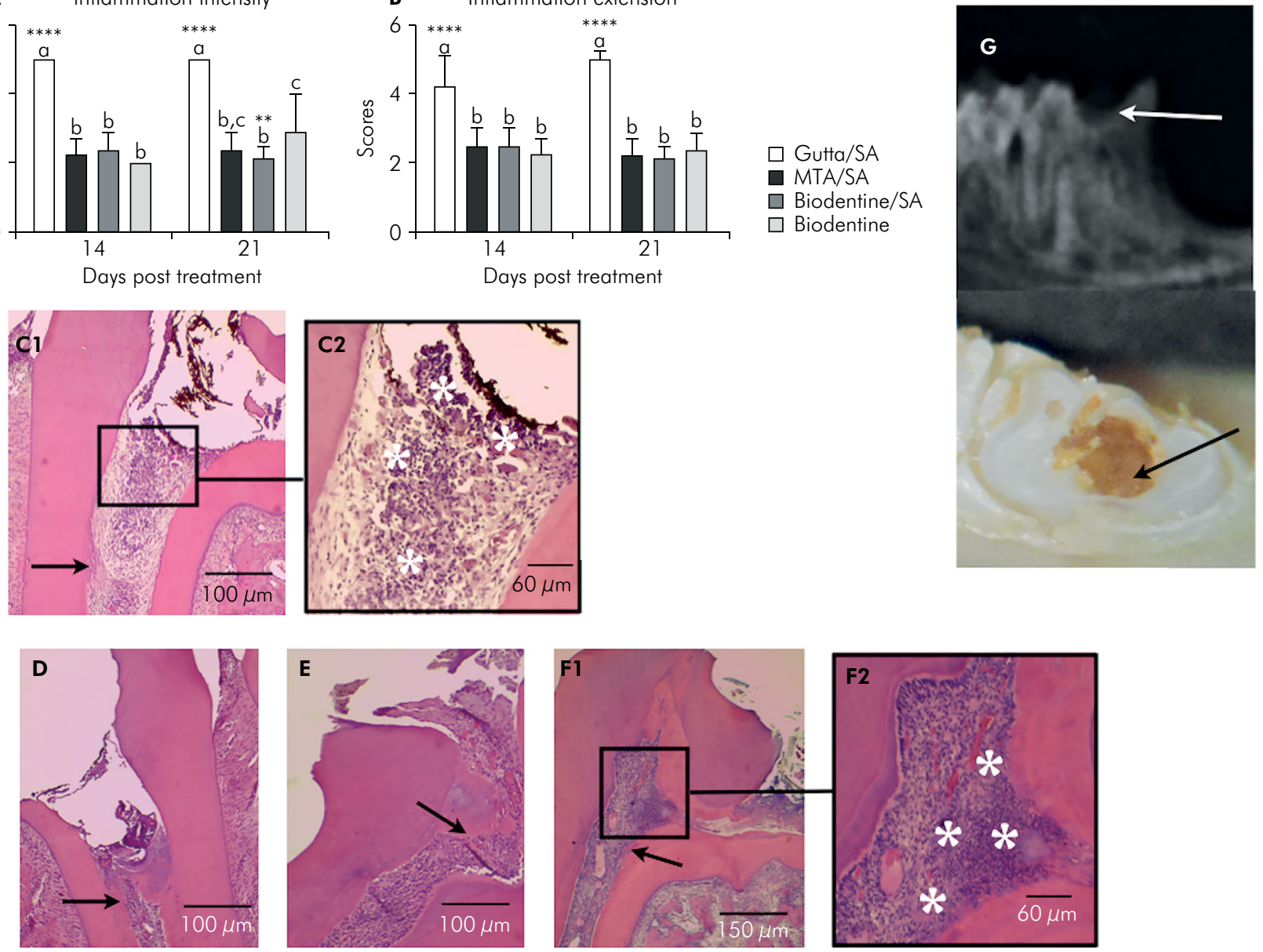

Figure 2. Inflammatory events after 14 and 21 days of pulp capping. Significant differences amongst groups (indicated by different letters) were assessed by Kruskal-Wallis and Dunn's post hoc tests at a significance level of.05. Significant differences in inflammation intensity (A) and extension (B) comparing the test groups with the positive control $(* * * * p<0.0001)$ were observed. In the 21 -day experimental period, samples capped with Biodentine alone (Biodentine group) showed more intense inflammatory infiltrate compared to the ones capped with Biodentine and sealed with silver amalgam (Biodentine/SA group) $\left({ }^{* *} p<0.01\right)$. (C) Sample capped with gutta-percha and sealed with SA showing abscess formation $\left({ }^{*}\right)$ and intense inflammatory infiltrate extending as far as the root canal middle third (arrow) after 21 days (H/E) Samples capped with MTA (D) and Biodentine (E) and sealed with SA 14 days after treatment. Note that the inflammatory infiltrate is limited to the coronal portion of the root (arrows) (H/E). (F) Sample capped and sealed with Biodentine showing intense inflammatory infiltrate $\left(^{*}\right)(H / E)$ associated with loss of coronal seal. (G) Radiographic and clinical image showing the loss of coronal seal.

This study comprised observations of semi-serial sections, not allowing the observation of the total dentin barrier formation. Nevertheless, it allowed comparisons of the patterns of hard tissue when in contact with MTA or Biodentine. Since the term dentin bridge has been universally used, we adopted them within the tables for reading easiness only. We are aware that this a limitation of this study, bearing in mind the difficulties to perform serial sections in minute tissues, like rats' dental pulp.
The small size of the teeth and difficulties related to cavity preparation and placement of biomaterials required some adaptations. Therefore, appropriate training, proper position of rat's head, mouth opening, and soft tissue removal were critical to carry out the procedures. The use of a previously designed device $^{36}$ to open and stabilize the rat mouth was also considered.

The simultaneous occurrence of inflammatory and degenerative events after pulp exposure and placement 

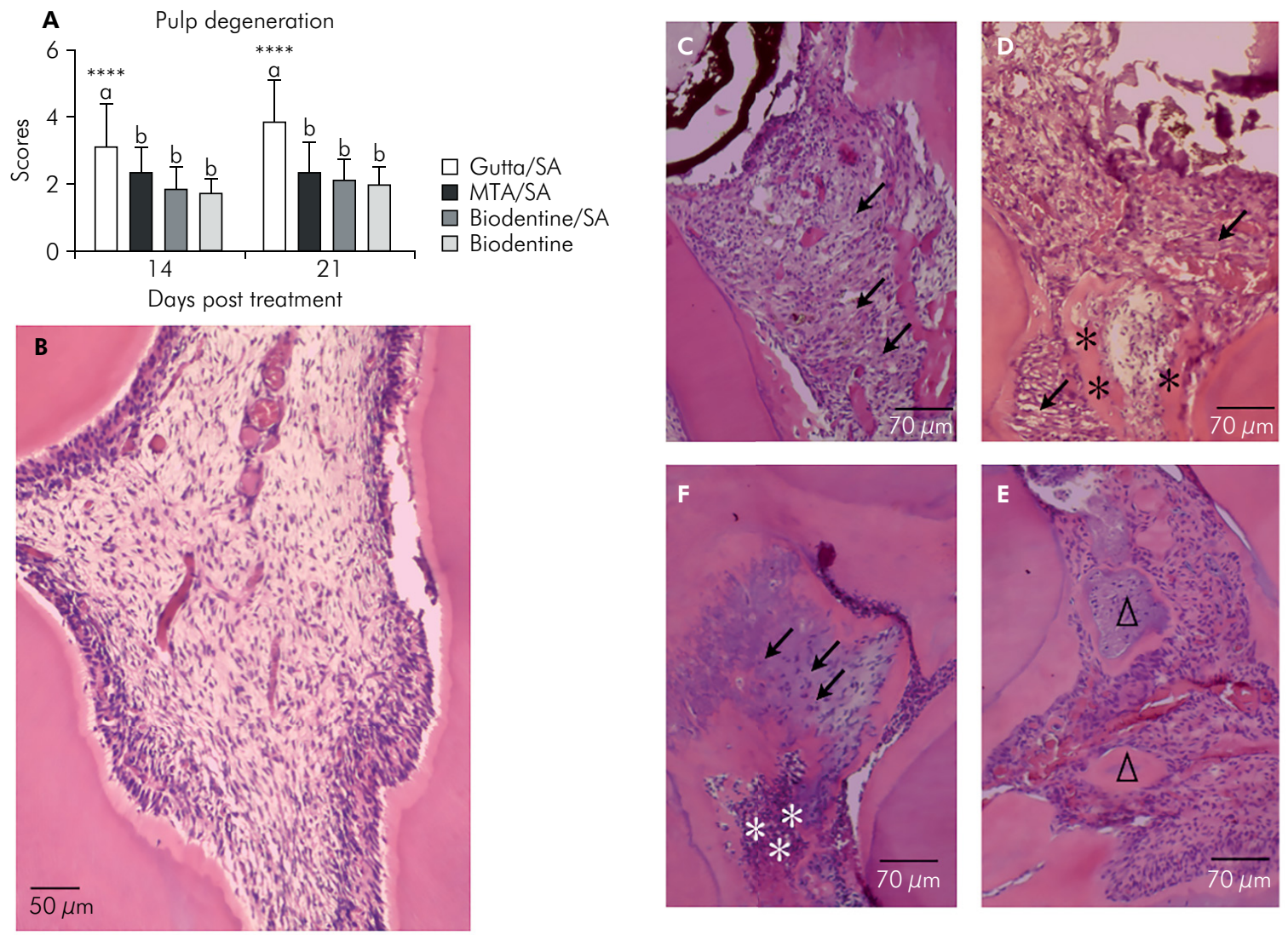

Figure 3. Degenerative events observed after capping procedures. (A) Significant differences were observed when test groups were compared with the positive control at both $14(\mathrm{P}<0.05)$ and 21 days $(P<0.01)$. (B) Untreated teeth served as control for the absence of pulp inflammation and/or degeneration, characterized by abundant cell content (H/E). (C) Sample capped with gutta-percha and sealed with SA 14 days after the procedures showing hyalinized area and reduction of dental pulp cell content (arrows) (H/E). (D) Specimen capped with MTA and sealed with SA at 21 days presenting pulp calcification (*) and fibrous condensation (arrows) $(H / E)$. (E) Pulp stones $(\triangle)$ and tissue hyalinization in a sample capped with Biodentine and sealed with SA at 21 days after treatment $(\mathrm{H} / \mathrm{E})$ (F) Specimen capped and sealed with Biodentine alone presenting both inflammatory infiltrate $\left({ }^{*}\right)$ and degenerative events (arrows) associated with loss of coronal seal after 21 days $(H / E)$.

of biomaterials was assessed through the comparison of pulp characteristics of negative control samples (healthy teeth). The presence of inflammatory cells and abscess together with fibrous condensation and hyalinized and calcified areas, as observed herein, characterizes pulp diseases as dynamic processes.,40 However, inflammation intensity is often used as the only measure of damage and comprehensive histological descriptions of pulp responses ${ }^{32}$ are not covered in most of the studies on vital pulp therapy. ${ }^{20}$

The positive control group showed the largest pulp degeneration and tissue necrosis. Most of the specimens in contact with MTA or Biodentine displayed moderate fibrous condensation, as well as small areas of hyalinization and of calcific degeneration. In some samples, there was extensive calcific degeneration or large areas of intrapulpal calcifications. Biodentine tended to favor the occurrence of pulp calcifications, although the differences when compared to the other groups were not statistically significant. Similarly, Tziafa et al. ${ }^{39}$ observed higher occurrence of pulp ectopic calcification in samples treated with Biodentine. MTA and Biodentine produced transient inflammatory reactions, which took place to a limited extent and at levels that positively influenced pulp repair and the formation of hard tissue barriers, differently from what was observed in the positive control group.

The formation of hard tissue barrier is an important factor in determining the outcome of vital pulp therapy, and the radiographic evaluation of dentin bridges 
- Pulp capping with mineral trioxide aggregate or Biodentine: a comparison of mineralized barrier formation and inflammatory and degenerative events
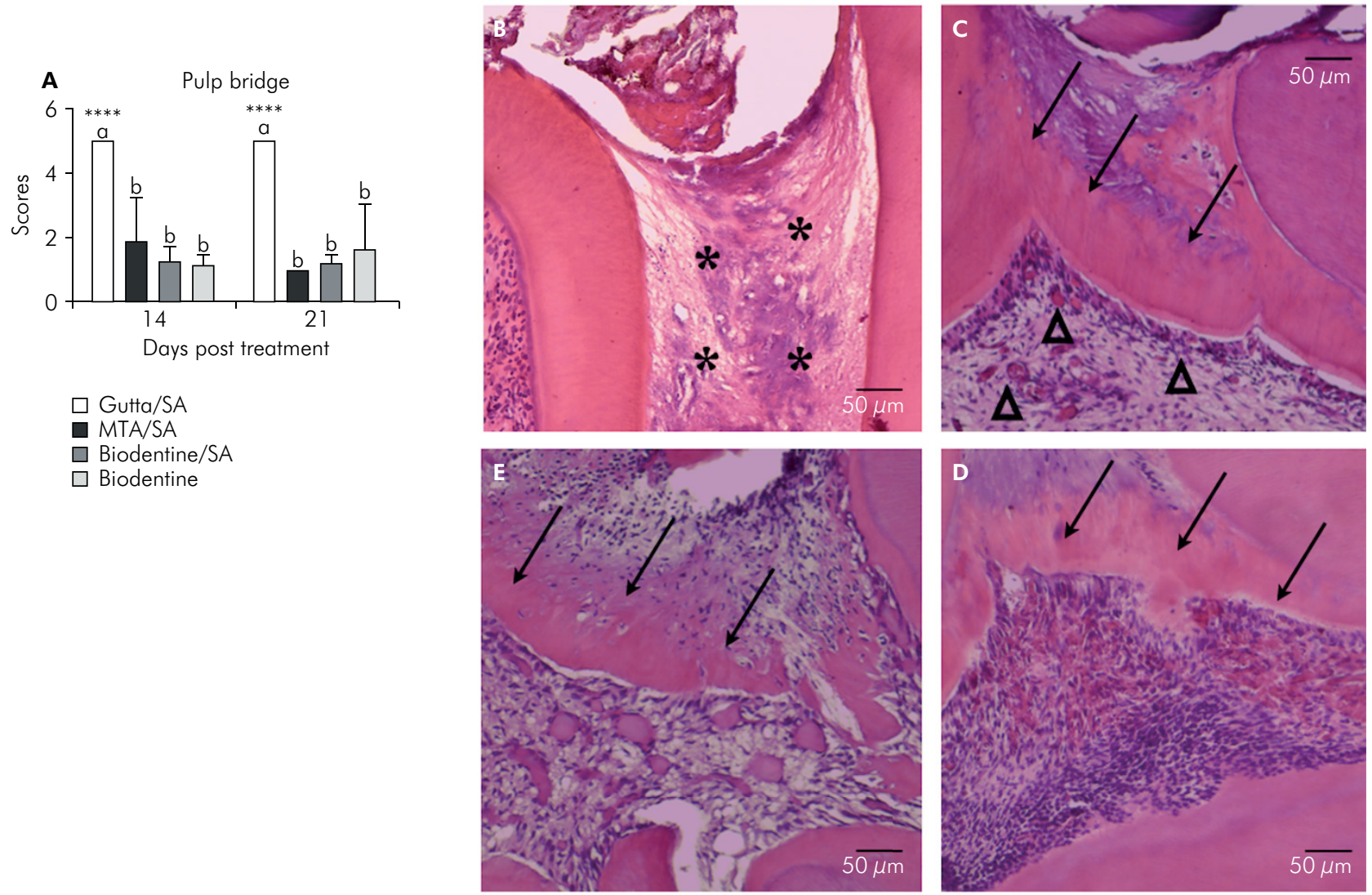

Figure 4. (A) Scores for pulp bridge formation after capping procedures. All test groups showed significant differences as compared to the control $(\mathrm{P}<0.0001)$; $(\mathrm{B})$ Sample capped with gutta-percha showing pulp necrosis $\left({ }^{*}\right)$ and absence of hard tissue barrier after 21 days $(\mathrm{H} / \mathrm{E})$; $(\mathrm{C})$ healed and well-vascularized tissue $(\triangle)$ associated with pulp bridge formation (arrows) at 21 days after pulp capping with MTA/SA (H/E); (D) Sample capped with Biodentine and sealed with silver amalgam at 14 days presenting thick and completely formed hard tissue barrier (arrows) (H/E); (E) Sample capped and sealed with Biodentine showing almost complete hard tissue barrier (arrows) after 14 days $(H / E)$.

is considered as a criterion for success. However, Awawdeh et al. ${ }^{41}$ showed that both Biodentine and MTA do not have sufficient radiopacity to be distinguished from a hard tissue barrier. In this regard, studies in animal models provide additional information to that from clinical trials.

Nowicka et al. ${ }^{20}$ observed reduced inflammation and formation of dentin-like tissue barriers in long postoperative periods after using MTA or Biodentine as capping agents. In this regard, mild pulp inflammation as an integral part of the process that leads to stem cell proliferation and differentiation ${ }^{3}$ was confirmed. The inflammation that precedes the formation of calcified barriers stimulates molecular signaling pathways, which can induce the proliferation and differentiation of dental pulp stem cells (DPSCs) into odontoblast-like cells, leading to the synthesis and secretion of a dentin-like matrix and its mineralization..$^{1,2,22}$ The formed hard tissue barriers in the test groups can be partially explained by the mineralization potential of MTA $^{4,5,6,8,42}$ and of Biodentine. ${ }^{21,38,39,42,43}$ These bioactive materials creates a high level of calcium ions diffusion and the formation of apatite precursor layers when in contact with body fluids. ${ }^{44}$ MTA and Biodentine are also capable to stimulate pulp stem cells migration and mineral deposition, ${ }^{2,4}$ thus favoring hard tissue formation trough continuous calcium release and apatite nucleation on the material surface. ${ }^{4}$

Moreover, a previous in vitro investigation revealed that, even when prepared at different concentrations, Biodentine is able to increase stem cell proliferation, migration, and adhesion, ${ }^{19}$ which might have favored 
the biological responses observed herein. The capacity of Biodentine to promote pulp mineralization in shorter periods than other materials has been suggested in an entirely human tooth culture model. ${ }^{18}$ Dental pulp cells in contact with Biodentine released TGF-B1 and formed mineralized foci in just 2 days, with osteodentin formation after 14 days.

In the current investigation, although Biodentine favored the formation of hard tissue barriers, this outcome did not occur earlier when compared to MTA samples. Moreover, although osteodentin zones have been previously described as a characteristic of dental bridges induced by Biodentine, ${ }^{39}$ this was not confirmed in the current study, mainly because the rat model does not allow observations at exactly the same sites to infer differences within dentin bridge characteristics. The outcomes presented herein confirmed the potential of Biodentine for inducing mineralization ${ }^{16,18,20,21,34}$ and maintaining pulp tissue health. ${ }^{38,39}$ The loss of seal in some samples did not affect this ability.

As with other investigations ${ }^{20,21,34,38}$ samples capped with either MTA or Biodentine promoted higher formation of incomplete and complete hard tissue barriers than the positive control group. Probably, Biodentine capacity of inducing biomineralization markers expression in an intense and large area of dental pulp ${ }^{42}$ have an influence on this material outcomes.

Keeping an efficient coronal seal is of paramount importance for avoiding infection and allowing vital pulp therapy success. ${ }^{6,20,32,35}$

The ability of Biodentine as a temporary restorative material has been previously tested in a study that evaluated furcation perforation in rat molars. ${ }^{37}$ In that study, slightly higher bone resorption was observed in teeth sealed with Biodentine in comparison to teeth sealed with silver amalgam. This may be due to contamination caused by lack of proper restoration.
As demonstrated in the present study, some samples sealed with Biodentine showed degradation or total loss of the restorative material at 21 days. However, a mineralized tissue barrier was not formed in only one of the samples, and the earlier establishment of the biological seal in most of the test group samples may explain this outcome. Nevertheless, gaps in the coronal seal could prevent long-term success of treatment through reinfection and reestablishment of pulp disease, which would probably occur if longer experimental periods were included. Although the rat model produces higher masticatory stress, which is characteristic of rodents, ${ }^{21}$ erosion of Biodentine restorations can occur in human posterior teeth..$^{23}$ These findings, along with evidence of material disintegration in the presence of blood or other fluids, ${ }_{13}^{13}$ contradict reports on compressive strength ${ }^{13,14}$ and of the suitability of Biodentine as a temporary restorative material. ${ }^{24,25}$ Thus, caution is necessary before deciding for its clinical use.

The present results confirm that Biodentine has favorable properties when used in vital pulp therapy and show its strong potential for inducing the formation of hard tissue barriers. Although the biological advantages of Biodentine over MTA were not clearly evidenced, easier handling and the perspective of avoiding tooth discoloration ${ }^{20,23,25}$ are favorable to the application of Biodentine in the dental practice. On the other hand, there were some limitations regarding coronal sealing ability and Biodentine should therefore be associated with a more efficient restorative material to ensure long-term positive outcomes.

\section{Conclusion}

Biodentine showed favorable properties in vital pulp therapy, being similar to MTA. However, its use as a temporary restorative material cannot be recommended.

\section{References}

1. Obeid M, Saber SD, Ismael AD, Hassanien E. Mesenchymal stem cells promote hard-tissue repair after direct pulp capping. J Endod. 2013 May;39(5):626-31. https://doi.org/10.1016/i.joen.2012.12.012

2. Paranipe A, Smoot T, Zhang H, Johnson JD. Direct contact with mineral trioxide aggregate activates and differentiates human dental pulp cells. J Endod. 2011 Dec;37(12):1691-5. https://doi.org/10.1016/i.joen.2011.09.012 
- Pulp capping with mineral trioxide aggregate or Biodentine: a comparison of mineralized barrier formation and inflammatory and degenerative events

3. Cooper PR, Takahashi Y, Graham LW, Simon S, Imazato S, Smith AJ. Inflammation-regeneration interplay in the dentine-pulp complex. J Dent. 2010 Sep;38(9):687-97. https://doi.org/10.1016/i.jdent.2010.05.016

4. Prati C, Gandolfi MG. Calcium silicate bioactive cements: biological perspectives and clinical applications. Dent Mater. 2015 Apr;31(4):351-70. https://doi.org/10.1016/i.dental.2015.01.004

5. Darvell BW, Wu RC. "MTA": an hydraulic silicate cement: review update and setting reaction. Dent Mater. 2011 May;27(5):407-22. https://doi.org/10.1016/j.dental.2011.02.001

6. Mente J, Hufnagel S, Leo M, Michel A, Gehrig H, Panagidis D, et al. Treatment outcome of mineral trioxide aggregate or calcium hydroxide direct pulp capping: long-term results. J Endod. 2014 Nov;40(11):1746-51. https://doi.org/10.1016/i.joen.2014.07.019

7. Parirokh M, Torabinejad M. Mineral trioxide aggregate: a comprehensive literature review_Part I: chemical, physical, and antibacterial properties. J Endod. 2010 Jan;36(1):16-27. https://doi.org/10.1016/i.joen.2009.09.006

8. Tabarsi B, Parirokh M, Eghbal MJ, Haghdoost AA, Torabzadeh H, Asgary S. A comparative study of dental pulp response to several pulpotomy agents. Int Endod J. 2010 Jul;43(7):565-71. https://doi.org/10.1111/i.1365-2591.2010.01711.x

9. Dammaschke T, Stratmann U, Wolff P, Sagheri D, Schäfer E. Direct pulp capping with mineral trioxide aggregate: an immunohistologic comparison with calcium hydroxide in rodents. J Endod. 2010 May;36(5):814-9. https://doi.org/10.1016/i.joen.2010.02.001

10. Lee SJ, Monsef M, Torabinejad M. Sealing ability of a mineral trioxide aggregate for repair of lateral root perforations. J Endod. 1993 Nov;19(11):541-4. https://doi.org/10.1016/S0099-2399(06)81282-3

11. Kundzina R, Stangvaltaite L, Eriksen HM, Kerosuo E. Capping carious exposures in adults: a randomized controlled trial investigating mineral trioxide aggregate versus calcium hydroxide. Int Endod J. 2017 Oct;50(10):924-32. https://doi.org/10.1111/iej.12719

12. Kang SH, Shin YS, Lee HS, Kim SO, Shin Y, Jung IY, et al. Color changes of teeth after treatment with various mineral trioxide aggregate-based materials: an ex vivo study. J Endod. 2015 May;41(5):737-41. https://doi.org/10.1016/i.joen.2015.01.019

13. Grech L, Mallia B, Camilleri J. Investigation of the physical properties of tricalcium silicate cement-based root-end filling materials. Dent Mater. 2013 Feb;29(2):e20-8. https://doi.org/10.1016/i.dental.2012.11.007

14. Han L, Okiii T. Bioactivity evaluation of three calcium silicate-based endodontic materials. Int Endod J. 2013 Sep;46(9):808-14. https://doi.org/10.1111/iej.12062

15. Camilleri J, Sorrentino F, Damidot D. Investigation of the hydration and bioactivity of radiopacified tricalcium silicate cement, Biodentine and MTA Angelus. Dent Mater. 2013 May;29(5):580-93. https://doi.org/10.1016/i.dental.2013.03.007

16. Chang SW, Lee SY, Ann HJ, Kum KY, Kim EC. Effects of calcium silicate endodontic cements on biocompatibility and mineralization-inducing potentials in human dental pulp cells. J Endod. 2014 Aug;40(8):1194-200. https://doi.org/10.1016/i.joen.2014.01.001

17. Formosa LM, Mallia B, Camilleri J. The effect of curing conditions on the physical properties of tricalcium silicate cement for use as a dental biomaterial. Int Endod J. 2012 Apr;45(4):326-36. https://doi.org/10.1111/j.1365-2591.2011.01980.x

18. Laurent $P$, Camps J, About I. Biodentine (TM) induces TGF- $\beta 1$ release from human pulp cells and early dental pulp mineralization. Int Endod J. 2012 May;45(5):439-48. https://doi.org/10.1111/j.1365-2591.2011.01995.x

19. Luo Z, Li D, Kohli MR, Yu Q, Kim S, He WX. Effect of Biodentine ${ }^{\mathrm{TM}}$ on the proliferation, migration and adhesion of human dental pulp stem cells. J Dent. 2014 Apr;42(4):490-7. https://doi.org/10.1016/i.jdent.2013.12.011

20. Nowicka A, Lipski M, Parafiniuk M, Sporniak-Tutak K, Lichota D, Kosierkiewicz A, et al. Response of human dental pulp capped with biodentine and mineral trioxide aggregate. J Endod. 2013 Jun;39(6):743-7. https://doi.org/10.1016/i.joen.2013.01.005

21. Tran XV, Gorin C, Willig C, Baroukh B, Pellat B, Decup F, et al. Effect of a calcium-silicate-based restorative cement on pulp repair. J Dent Res. 2012 Dec;91(12):1166-71. https://doi.org/10.1177/0022034512460833

22. Zanini M, Sautier JM, Berdal A, Simon S. Biodentine induces immortalized murine pulp cell differentiation into odontoblast-like cells and stimulates biomineralization. J Endod. 2012 Sep;38(9):1220-6. https://doi.org/10.1016/i.joen.2012.04.018

23. Koubi G, Colon P, Franquin JC, Hartmann A, Richard G, Faure MO, et al. Clinical evaluation of the performance and safety of a new dentine substitute, Biodentine, in the restoration of posterior teeth - a prospective study. Clin Oral Investig. 2013 Jan;17(1):243-9. https://doi.org/10.1007/s00784-012-0701-9

24. Koubi S, Elmerini H, Koubi G, Tassery H, Camps J. Quantitative evaluation by glucose diffusion of microleakage in aged calcium silicate-based open-sandwich restorations. Int J Dent. 2012;2012(2):105863. https://doi.org/10.1155/2012/105863

25. Raskin A, Eschrich G, Dejou J, About I. In vitro microleakage of Biodentine as a dentin substitute compared to Fuji II LC in cervical lining restorations. J Adhes Dent. 2012 Dec;14(6):535-42.

26. Petta TM, Pedroni AC, Saavedra DF, Faial KD, Marques MM, Couto RS. The effect of three different pulp capping cements on mineralization of dental pulp stem cells. Dent Mater J. 2020 Mar;39(2):222-8. https://doi.org/10.4012/dmj.2018-349

27. Silva LA, Pieroni KA, Nelson-Filho P, Silva RA, Hernandéz-Gatón P, Lucisano MP, et al. Furcation perforation: perirradicular tissue response to Biodentine as a repair material by histopathologic and indirect immunofluorescence analyses. J Endod. 2017 Jul;43(7):1137-42. https://doi.org/10.1016/i.joen.2017.02.001

28. Cardoso M, Dos Anjos Pires M, Correlo V, Reis R, Paulo M, Viegas C. Biodentine for furcation perforation repair: an animal study with histological, radiographic and micro-computed tomographic assessment. Iran Endod J. 2018;13(3):323-30. 
29. Fonseca TS, Silva GF, Guerreiro-Tanomaru JM, Delfino MM, Sasso-Cerri E, Tanomaru-Filho M, et al. Biodentine and MTA modulate immunoinflammatory response favoring bone formation in sealing of furcation perforations in rat molars. Clin Oral Investig. 2019 Mar;23(3):1237-52. https://doi.org/10.1007/s00784-018-2550-7

30. Cuadros-Fernández C, Lorente Rodríguez Al, Sáez-Martínez S, García-Binimelis J, About I, Mercadé M. Short-term treatment outcome of pulpotomies in primary molars using mineral trioxide aggregate and Biodentine: a randomized clinical trial. Clin Oral Investig. 2016 Sep;20(7):1639-45. https://doi.org/10.1007/s00784-015-1656-4

31. Taha NA, Abdelkhader SZ. Outcome of full pulpotomy using Biodentine in adult patients with symptoms indicative of irreversible pulpitis. Int Endod J. 2018 Aug;51(8):819-28. https://doi.org/10.1111/iej.12903

32. Dondoni L, Scarparo RK, Kantarci A, Van Dyke TE, Figueiredo JA, Batista Junior EL. Effect of the pro-resolution lipid mediator Resolvin El (RvE1) on pulp tissues exposed to the oral environment. Int Endod J. 2014 Sep;47(9):827-34. https://doi.org/10.1111/iej.12224

33. Salako N, Joseph B, Ritwik P, Salonen J, John P, Junaid TA. Comparison of bioactive glass, mineral trioxide aggregate, ferric sulfate, and formocresol as pulpotomy agents in rat molar. Dent Traumatol. 2003 Dec;19(6):314-20. https://doi.org/10.1046/j.1600-9657.2003.00204.x

34. Tran XV, Salehi H, Truong MT, Sandra M, Sadoine J, Jacquot B, et al. Reparative mineralizes tissue characterization after direct pulp capping with calcium-silicated-based cements. Mater. 2019 Jun;12(13):1-11. https://doi.org/10.3390/ma12132102

35. Kakehashi S, Stanley HR, Fitzgerald RJ. The effects of surgical exposures of dental pulps in germ-free and conventional laboratory rats. Oral Surg Oral Med Oral Pathol. 1965 Sep;20(3):340-9. https://doi.org/10.1016/0030-4220(65)90166-0

36. Scarparo RK, Dondoni L, Böttcher DE, Grecca FS, Rockenbach MI, Batista EL Jr. Response to intracanal medication in immature teeth with pulp necrosis: an experimental model in rat molars. J Endod. 2011 Aug;37(8):1069-73. https://doi.org/10.1016/j.joen.2011.05.014

37. Reis MS, Scarparo RK, Steier L, Figueiredo JA. Periradicular inflammatory response, bone resorption, and cementum repair after sealing of furcation perforation with mineral trioxide aggregate (MTA Angelus ${ }^{\text {TM }}$ ) or Biodentine ${ }^{\text {TM }}$. Clin Oral Investig. 2019 Nov;23(11):4019-27. https://doi.org/10.1007/s00784-019-02833-z

38. De Rossi A, Silva LA, Gatón-Hernández P, Sousa-Neto MD, Nelson-Filho P, Silva RA, et al. Comparison of pulpal responses to pulpotomy and pulp capping with biodentine and mineral trioxide aggregate in dogs. J Endod. 2014 Sep;40(9):1362-9. https://doi.org/10.1016/i.joen.2014.02.006

39. Tziafa C, Koliniotou-Koumpia E, Papadimitriou S, Tziafas D. Dentinogenic responses after direct pulp capping of miniature swine teeth with Biodentine. J Endod. 2014 Dec;40(12):1967-71. https://doi.org/10.1016/i.joen.2014.07.021

40. Seltzer S, Bender IB, Ziontz M. The dynamics of pulp inflammation: correlations between diagnostic data and actual histologic findings in the pulp. Oral Surg Oral Med Oral Pathol. 1963 Jul;16(7):846-71. https://doi.org/10.1016/0030-4220(63)90323-2

41. Awawdeh L, Al-Qudah A, Hamouri H, Chakra RJ. Outcomes of vital pulp therapy using Mineral Trioxide Aggregate or Biodentine: a prospective randomized clinical trial. J Endod. 2018 Nov;44(11):1603-9. https://doi.org/10.1016/i.joen.2018.08.004

42. Daltoé MO, Paula-Silva FW, Faccioli LH, Gatón-Hernández PM, De Rossi A, Bezerra Silva LA. Expression of mineralization markers during pulp response to biodentine and mineral trioxide aggregate. J Endod. 2016 Apr;42(4):596-603. https://doi.org/10.1016/i.joen.2015.12.018

43. Rajasekharan S, Martens LC, Cauwels RG, Verbeeck RM. Biodentine ${ }^{T M}$ material characteristics and clinical applications: a review of the literature. Eur Arch Paediatr Dent. 2014 Jun;15(3):147-58. https://doi.org/10.1007/s40368-014-0114-3

44. Camilleri J, Grech L, Galea K, Keir D, Fenech M, Formosa L, et al. Porosity and root dentine to material interface assessment of calcium silicate-based root-end filling materials. Clin Oral Investig. 2014;18(5):1437-46. https://doi.org/10.1007/s00784-013-1124-y 